\title{
Ряпина Н.Е. \\ Коммуникативный подход как наиболее эффективный метод обучения говорению студентов экономических специальностей
}

Пермский государственный наџиональный исследовательский университет

(Россия, Пермь)

doi: $10.18411 / l j-30-11-2017-18$

idsp: 000001:lj-30-11-2017-18

\section{Аннотация}

В статье рассматривается процесс обучения говорению студентов экономических специальностей. Показано, что коммуникативный подход является наиболее эффективным при формировании коммуникативной компетенции, которая необходима при межкультурной коммуникации. Особое внимание уделяется описанию особенностям использования коммуникативного метода при обучении студентов говорению. Подчеркивается, что сформированная межкультурная коммуникативная компетенция является конкурентным преимуществом студентов на рынке труда.

Ключевые слова: говорение, коммуникативный подход, коммуникативная компетенция, межкультурная коммуникация, языковой барьер, культурные нормы, конкурентное преимущество.

\section{Abstract}

The article deals with the process of teaching speaking skills to students of the faculty of economics. The communicative approach is presented as the most effective in the process of communicative competence formation which is essential for intercultural communication. It can be really useful in overcoming the language barrier and stimulating the process of speaking. It is specially noted that if students have intercultural communicative competence they have the ability to understand cultures, and use this understanding to communicate with people from other cultures successfully. As a result they have competitive advantage in the labour market.

Keywords: speaking skills, communicative approach, communicative competence, intercultural communication, language barrier, cultural norms, competitive advantage.

Невозможно представить современное общество без общения между людьми. Взаимодействие может происходить между людьми одной национальности, или же между представителями разных культур.

Говоря о межкультурной коммуникации, В.С. Библер, отмечает, что она как бы порождает «новый всеобщий социум культуры», особую социальность, точнее форму свободного общения людей в силовом поле диалога культур[1].

В современном мире представители разных культур общаются, используя разнообразные формы коммуникации. Наибольшее значение для людей имеет вербальное общение, средством которого является устная и письменная речь.

Следовательно, владение иноязычной речевой деятельностью может быть названо средством эффективного межкультурного взаимодействия, а ведущим языком международного общения сегодня является английский.

В соответствие с самостоятельно устанавливаемым образовательным стандартом высшего образования (СУОС ВО) Пермского государственного национального исследовательского университета в рамках курса изучения иностранного языка, у студента направления подготовки 38.03.01 (Экономика) должна быть сформирована общекультурная компетенция, а именно, студент должен «владеть базовой лексикой и грамматикой одного из иностранных языков, основами разговорной речи; уметь читать тексты на общеобразовательные и профессиональные темы, передавать их содержание на русском и иностранном языках» [2]. 
Как мы можем видеть, требования к овладению иностранным языком достаточно невысоки. Но, тем не менее, современные молодые люди стремятся овладеть английским языком на более высоком уровне, чтобы быть полноценными участниками межкультурного общения в разных сферах.

Студенты заинтересованы в формировании навыков общения на английском языке, необходимых в различных ситуациях, начиная от ситуаций бытового общения и заканчивая общением на узкопрофессиональные темы.

Будущие экономисты осознают тот факт, что на рынке труда профессия экономиста не востребована в связи с огромным количеством специалистов в этой сфере. Таким образом, если выпускник владеет английским языком и может свободно общаться, он становится более конкурентоспособным. Знание языка может быть названо его конкурентным преимуществом.

Межкультурная коммуникация - это сложный многоуровневый процесс, который включает в себя огромное количество элементов. Это не только процесс говорения, понимания и правильной интерпретации информации, но также умение понять особенности культуры собеседника, правильное использование и восприятие языка жестов и знание правил этикета. Студент, стремящийся к успешному общению на иностранном языке должен овладеть коммуникативной компетенцией.

Термин «коммуникативная компетенция» был введен Д. Хаймсом. Коммуникативную компетенцию Д. Хаймс определяет как внутреннее знание ситуационной уместности языка; как способности, позволяющие быть участником речевой деятельности. Д. Хаймс одним из первых наглядно показал, что владение языком предполагает знание не только грамматики и лексики, но и социальных условий их употребления [3].

Для достижения этой цели представляется разумным использовать коммуникативный подход при обучении говорению студентов, так как он подразумевает не только изучение непосредственно языка, но и изучение поведения в обществе, то есть социального поведения. Также, внимание уделяется изучению культуры страны изучаемого языка.

На практике можно заметить, что межкультурное общение у студентов часто ассоциируется только лишь с процессом говорения, а ситуативная уместность языка отходит на задний план.

Перед преподавателем стоит задача объяснить студенту, что полноценное общение невозможно без понимания ситуации общения, без учета норм поведения носителей языка, без знания культуры страны изучаемого языка. Необходимо не только стремиться понимать смысл высказываний и уметь реагировать в ответ, но и узнавать культуру страны через изучаемый язык. Если это происходить, то коммуникация выходит на качественно другой уровень, и психологический барьер при говорении и восприятии иностранной речи исчезает.

Обучение говорению, которое является необходимым аспектом изучения английского языка, часто проходит достаточно сложно, так как отсутствие языковой среды и достаточной практики общения приводит к возникновению психологического барьера, который студенту достаточно сложно преодолеть. Даже для студента с достаточно высоким уровнем владения языком бывает сложно поддерживать коммуникацию даже со студентами своей учебной группы, не говоря уже о носителях языка.

Как мы видим, преподаватель английского языка сталкивается с непростой задачей. С одной стороны преподавателю нужно создать атмосферу общения комфортную для студента, и, в тоже время, она должна быть максимально приближена к ситуации общения в естественной среде, которая не всегда понятна молодому человеку. 
В зависимости от уровня группы, сложность заданий для развития навыка говорения и формирование коммуникативной компетенции может быть разной.

Если уровень владения языком достаточно невысокий, то каждый урок может быть посвящен отдельной ситуации. Например, студенту нужно спросить дорогу до определенного места и уметь также объяснить, как добраться. Преподавать может провести подготовительный этап, вспомнив правила построения вопроса, подходящего для данной ситуации, повторить фразы вежливого обращения к незнакомому человеку, вспомнить слова и словосочетания по этой теме.

Только после этого студент может попробовать себя и в роли человека спрашивающего дорогу и в роли человека объясняющего как пройти куда-либо. Чтобы ситуация была более естественной преподаватель может попросить студентов придумать историю персонажей, участвующих в диалоге. Например, один может быть иностранным студентом, а другой — местным жителем.

«Иностранный студент» может рассказать о проблемах, с которыми он сталкивается, а «местный житель» описать положительный стороны жизни в его стране.

В более сильной группе можно разыграть день из жизни вымышленного персонажа. Представить, как человек общается с семьей, например, за завтраком, с детьми по дороге на работу, какие ситуации делового общения возникают в его профессиональной деятельности днем, и как он проводит досуг вечером.

Предварительно можно дать задания группам студентов подготовить доклады о разных сторонах жизни людей страны изучаемого языка. Интересно представить информацию о бытовых моментах, о взаимоотношениях в семье, о контактах на работе, о культурных ценностях и вариантах проведения свободного времени.

Изучению этой информации можно посвятит не одно, а ряд занятий. И только после того, как у студентов сложилось представление о жизни в стране изучаемого языка, они могут воспроизводить сцены из жизни людей этой страны.

Представляется интересным изучение одних и тех же аспектов жизни представителей разных классов общества.

Студентов нужно сориентировать на получение информации из разных источников, например, не только из журналов и газет, а также из фильмов и художественной литературы, из информации, доступной в Интернете, а, при возможности, и из общения с носителями языка.

Студентом можно дать задание пообщаться и получить информацию из первых рук, то есть от носителей языка, используя сервисы для общения с носителями языка. Например, им можно посоветовать использовать сервис Mylanguageexchange, где можно пообщаться с пользователями из более 133 стран, выбрав понравившегося собеседника. Также интересен сайт italki.com, где студент может записаться на урок по интересующей его теме к носителю языка. Все более популярным становится сайт InterPals, который, по сути, представляет огромное интернациональное сообщество, где люди могут общаться на разные темы.

Проработав таким образом так называемую фоновую информацию, студенты уже смогут воспроизвести ситуации общения более осознано и процесс коммуникации будет более эффективным.

Не стоит забывать, что хотя процесс изучение правил и заучивание новой лексики не является основным при использовании коммуникативного метода, но он может быть назван важным вспомогательным элементом, особенно, на начальном уровне изучения языка.

Если студенты понимают, например, правила построения вопроса или ориентируются в синтаксической структуре предложения, это значительно облегчает задачу построения высказывания и приводит к более продуктивному общению. Лексика по теме также необходима. Ее активное запоминание должно быть неотъемлемой составляющей процесса обучения говорению. 
Таким образом, использование коммуникативного подхода при обучении говорению может быть очень эффективно и способствовать формированию коммуникативной компетенции при условии использования вспомогательных элементов, таких как изучение грамматики и лексики.

$$
* * *
$$

1. Библер В.С. От наукоучения к логике культуры. - Политиздат, 1991. С.417

2. Самостоятельно устанавливаемый образовательный стандарт высшего образования ПГНИУ. Направление подготовки 38.03.01 Экономика, 2016. - 38 с.

3. Гез Н. И., Фролова Г. М. История зарубежной методики преподавания иностранных языков Академия, 2008. - С. 256. 